Matthew H. Kramer*

\title{
The Demandingness of Deontological Duties: Is the Absolute Impermissibility of Placatory Torture Irrational?
}

https://doi.org/10.1515/mopp-2018-0045

\begin{abstract}
Consequentialist doctrines have often been criticized for their excessive demandingness, in that they require the thorough instrumentalization of each person's life as a vehicle for the production of good consequences. In turn, the proponents of such doctrines have often objected to what they perceive as the irrationality of the demandingness of deontological duties. In this paper, I shall address objections of the latter kind in an effort to show that they are unfounded. My investigation of this matter will unfold by reference to a scenario that strikingly and concretely exemplifies the demandingness of deontological duties. That scenario, which involves a situation of torture (specifically, placatory torture - in other words, torture undertaken for the purpose of appeasing people who have demanded that it be administered), will serve as a springboard for my endeavor to vindicate the rationality of deontological absolutes and will help to illuminate the endeavor's practical implications.
\end{abstract}

Keywords: deontology, consequentialism, practical rationality, morality, moral duties, moral absolutes, torture, moral integrity, Samuel Scheffler

Consequentialist doctrines have often been criticized for their excessive demandingness, in that they require the thorough instrumentalization of each person's life as a vehicle for the production of good consequences. In turn, the proponents of such doctrines have often objected to what they perceive as the irrationality of the demandingness of deontological duties. In this paper, I shall address objections of the latter kind in an effort to show that they are unfounded. My investigation of this matter, which will eventuate in some sustained animadversions on Samuel Scheffler's much-discussed indictment of the rationality of deontology, will unfold by reference to a scenario that strikingly and concretely exemplifies the demandingness of deontological duties. That scenario, which involves a situation of torture (specifically, placatory torture - in other words, torture undertaken for the purpose of appeasing people

*Corresponding author: Matthew H. Kramer, University of Cambridge, Churchill College CB3 ODS, Cambridge, United Kingdom, E-mail: mhk11@cam.ac.uk 
who have demanded that it be administered), will serve as a springboard for my endeavor to vindicate the rationality of deontological absolutes and will help to illuminate the endeavor's practical implications.

\section{Setting the stage}

Before we turn to that scenario of placatory torture, however, this paper will set the stage for all its subsequent meditations by clarifying some of my terminology and by tersely expounding the distinction between deontology and consequentialism. Let us begin with the terminological clarifications.

\subsection{Moral conflicts, moral permissibility, deontic stringency, and optimality}

Through much of this paper, I will be pondering situations that amount to moral conflicts. Like many other philosophers, I use the phrase 'moral conflict' to denote any situation in which someone is under a moral duty to $\varphi$ and simultaneously under a moral duty not to $\varphi$. (The variable ' $\varphi$ ' stands for any verb or verb phrase that refers to any action or omission.) Again like many other philosophers, I additionally use the phrase 'moral conflict' to denote any situation (i) where someone is under a moral duty to do $x$ and simultaneously under a moral duty to do $y$ and (ii) where doing $x$ is inconsistent with doing $y$. In a moral conflict of the latter kind, the contents of the conflicting duties are contraries rather than contradictories.

Slightly more involuted is the matter of moral permissibility. Crucial here is a distinction between two broad types of permissibility, which can best be approached through a distinction between two main kinds of moral duties. ${ }^{1}$ An overtoppingly stringent moral requirement exceeds in stringency all the moral duties with which it conflicts, or is not in conflict with any other moral duties. A non-overtoppingly stringent moral requirement $R$ does not exceed in stringency all the moral duties that conflict with it. (Any competing moral requirements might be equal in importance to $R$, or they might exceed it in importance, or they might be insusceptible to any determinate comparisons with it because of problems of incommensurability.)

1 For some more expansive accounts of the distinction between strong permissibility and weak permissibility, see Kramer (2014, pp. 4-7, 2016, pp. 165-8). 
Now, with reference to this dichotomy between overtopping and non-overtopping duties, we can differentiate between weak permissibility and strong permissibility:

Weak Permissibility. Some person $X$ is permitted to perform some action $q$ if and only if $X$ is not under any overtoppingly stringent obligation to not perform $q .^{2}$

$X$ 's being weakly permitted to perform $q$ is consistent with the proposition that $X$ is under a non-overtoppingly stringent obligation to not perform $q$. In that respect, weak permissibility differs from strong permissibility.

Strong Permissibility. $X$ is permitted to perform $q$ if and only if $X$ is neither under an overtoppingly stringent obligation to not perform $q$ nor under a non-overtoppingly stringent obligation to not perform $q$.

$X$ 's being strongly permitted to perform $q$ is inconsistent with the proposition that $X$ is under a non-overtoppingly stringent obligation to not perform $q$. Note that the proposition ' $X$ is strongly permitted to perform $q$ ' entails the proposition ' $X$ is weakly permitted to perform $q$ ', but not vice versa.

Whenever this essay uses the term 'permissible' or 'permissibility' without any qualification, it is invoking the notion of permissibility in the strong sense. Consequently, the term 'impermissible' is to be understood herein as 'not strongly permissible'. That is, I generally assume that an action $q$ is impermissible for a person $X$ unless $X$ is not under any obligation whatsoever to not do $q$. Moreover, 'wrong' and 'impermissible' are interchangeable terms in this essay; a course of conduct is morally wrong unless it does not contravene any moral duties.

In my exposition of the two broad types of permissibility, I have adverted repeatedly to the property of deontic stringency. That property can be understood in several ways, ${ }^{3}$ and a choice among those ways is not necessary for my purposes in this paper. By any reckoning, deontic stringency is a measure of the moral importance of a duty. Still, worth indicating here is the conception of stringency that implicitly underlies my numerous invocations of that notion. The stringency of a moral duty is given by the onerousness or sizeableness of the step(s) required in order to remedy a contravention of the duty. If the remedial obligations engendered by contraventions of some duty $\mathrm{D}_{1}$ are heavier than the

2 To avoid ambiguities in my prose, my placement of 'not' will create some ugly split infinitives at several junctures in this essay.

3 For a perceptive exploration of the matter, see Kamm (2007, ch. 8). 
remedial obligations engendered by contraventions of some other duty $\mathrm{D}_{2}$, then $\mathrm{D}_{1}$ is more stringent than $\mathrm{D}_{2}{ }^{4}$

One further point of preliminary terminological clarification pertains to the adjective 'optimal'. Although that term (or the synonymous term 'best') is evaluative, it is not to be understood along consequentialist lines here or elsewhere in this essay. Optimality is instead a function of deontic stringency. If someone's moral duty-to- $\varphi$ conflictingly coexists with her moral duty-not-to- $\varphi$, and if the stringency of the former duty is greater than that of the latter, her fulfillment of the duty-to- $\varphi$ is the lone morally optimal course of conduct for her in the circumstances. If the two duties are instead equally stringent, then her fulfillment of either of them is morally optimal in the circumstances. If her dutyto- $\varphi$ is not countervailed by any conflicting moral requirements, compliance with that duty is both morally optimal and strongly permissible.

\subsection{Deontology versus consequentialism}

Let us now turn to the distinction between deontological moral theories and consequentialist moral theories. We should mull over two main ways in which that distinction can be drawn.

\subsubsection{Intrinsic moral statuses}

One tack for differentiating between deontology and consequentialism is to concentrate on the moral statuses of modes of conduct (Kramer 2014, pp. 20f). If a course of conduct on the part of any person $\mathrm{P}$ is covered by a deontological permission, then P's engaging in that conduct is not wrong in any respect regardless of the consequences that it causes or is likely to cause. Within the ambit of the deontological permission, P's undertaking of the specified conduct does not breach any moral duties. Hence, within that ambit, his behavior is strongly permissible irrespective of the probable consequences of its occurrence. Suppose, for example, that $\mathrm{P}$ in any ordinary circumstances is deontologically at liberty to expend a certain portion of his income on his hobby of collecting stamps. Suppose further that any number of consequentialist objectives (such as the maximization of human happiness or the promotion of equal economic opportunities) would be advanced if $\mathrm{P}$ were instead to expend that portion of

4 This conception of stringency is integrally connected to the account of moral rights which I have propounded in Kramer (2004, ch. 8). 
his income on donations to charities. Notwithstanding that his pursuit of his philatelic hobby will bring about a worse state of affairs than he is capable of bringing about through alternative uses of his resources, $\mathrm{P}$ is not committing any wrongs so long as he is acting within the scope of the deontological prerogative which encompasses that pursuit.

Whereas an activity covered by a deontological prerogative is morally permissible regardless of the likely consequences of its occurrence, modes of conduct forbidden by deontological duties are morally impermissible regardless of the benignity of the consequences that are likely to flow from the occurrence of any such modes of conduct. If $\mathrm{P}$ is under a deontological duty to $\varphi$, then his not $\varphi$-ing is wrong regardless of how valuable the state of affairs that would result from his not $\varphi$-ing might be. That is, every deontological duty proscribes some course of conduct even if one's adoption of that course of conduct in particular circumstances would yield much better consequences than one's refraining therefrom.

While deontologists ascribe consequence-independent moral bearings to various actions and omissions, consequentialists of course maintain that the moral character of any type or instance of conduct is fully determined by the probable or actual consequences thereof. ${ }^{5}$ In the eyes of the latter theorists, no type or instance of conduct is ever endowed with any inherent moral status. Instead, every action or omission derives its moral status from the effects with which it is associated. Accordingly, as John Finnis has aptly remarked, a proponent of any consequentialist doctrine 'holds himself ready to do anything' (Finnis 1980, p. 121, emphasis in original). For the consequentialist, there are no principled limits on the range of actions that can legitimately be undertaken in sundry circumstances. The breadth or narrowness of that range will depend entirely on the results that are likely to follow from each of the multitudinous modes of conduct that might be adopted by people in any number of contexts. No mode of conduct, however abhorrent it may be, is unconditionally disallowed by the reckoning of a consequentialist theorist.

\subsubsection{Agent-neutrality versus agent-centeredness}

One way of differentiating between deontology and consequentialism, then, addresses the question whether the basic moral statuses of some patterns of

5 I am of course here assuming that the types or instances of conduct are specified without reference to the desideratum or set of desiderata pursued by any consequentialist theory that is under consideration. 
behavior are intrinsic or extrinsic. Another way - which has become especially prominent during the past few decades and which figures conspicuously in some of the philosophical literature on torture - pertains to the manner in which many of our fundamental moral obligations present their demands (Kramer 2014, pp. 21f). Whereas deontologists contend that those demands are agent-centered, ${ }^{6}$ consequentialists maintain that they are agent-neutral. In other words, deontological duties are such that they present each agent with reasons specifically for that agent to conduct himself in certain ways. The reasons do not pertain to goals by reference to which every agent is enjoined to produce maximally valuable or minimally disvaluable states of affairs. For example, a deontological duty to refrain from the crime of murder is not a duty to pursue an overarching goal such as the minimization of the number of murders in a society. Rather, it is a duty that requires each person to refrain from committing any murders even when his perpetration of such crimes would reduce their overall incidence or would otherwise be highly valuable. One's fulfillment of a deontological obligation consists not in one's venturing alongside other people to maximize the realization of some objective, but instead in one's compliance with a strict prohibition regardless of how other people might respond.

By contrast, consequentialist obligations require each person to act alongside other people to maximize the realization of some goal or array of goals (which might be highly pluralistic). A consequentialist obligation is agent-neutral in that it presents everyone with reasons-for-action that do not single him or her out as a particular person distinct from everybody else. In that respect, the reasons flowing from any consequentialist duty are fundamentally the same for everyone - though, naturally, the detailed specificities of what is required of each person will depend on his or her aptitudes and circumstances. In regard to any desideratum or set of desiderata upheld by such a duty, a maximizing quest is prescribed. From a consequentialist perspective, the attainment of the most valuable state of affairs possible is always better than the attainment of any less valuable state of affairs and is therefore both obligatory and strongly permissible. Everyone alike is morally obligated and morally at liberty to contribute to the achievement of that maximally valuable state of affairs, even if someone's contribution will involve his acting at odds with the content of a deontological principle. (Of course, although any consequentialist theory maintains that the maximization of some desideratum or set of desiderata is morally obligatory and

\footnotetext{
6 See, for example, Nagel (1979, pp. 132ff); Scheffler (1985); Darwall (1986). The epithet 'agentrelative' is also common in the relevant literature - owing largely to Parfit (1984, p. 143) and Nagel (1986, p. 152) - but I eschew it in order to make fully clear that a deontological conception of moral duties has nothing to do with moral relativism.
} 
permissible, not every such theory recommends that individuals adopt maximizing outlooks when arriving at decisions. Many consequentialists instead hold that the maximization of a favored desideratum or set of desiderata is best pursued indirectly through the focusing of individuals' choices and deliberations on other concerns. For example, the sway of a satisficing mentality among individuals in relation to some desideratum might be the best way for them to maximize their attainment of a more complex balance of desiderata.)

\subsubsection{Absolute prohibitions}

Such, then, are the two ways of distinguishing between deontology and consequentialism. Now, as is plain, those two ways are not identical. One of them addresses the question whether the basic moral statuses of certain modes of conduct are intrinsic or extrinsic, ${ }^{7}$ whereas the other addresses the question whether the reasons presented by many fundamental moral obligations are agent-centered or agent-neutral. Nonetheless, although the two versions of the deontology/consequentialism distinction are not exactly the same, they are not really separate; the latter version is a corollary of the former. If the basic moral status of a mode of conduct is consequence-independent, then - in the manner captured by the notion of agent-centeredness - that basic moral status is impervious to any consequentialist balancing that would deem the tokens of an abhorrent act-type AT to be permissible whenever those tokens can lower the overall incidence of AT. Imperviousness to such balancing is a key aspect of the general consequence-independence of an act-type's wrongness.

The distinction between deontology and consequentialism has a crucial bearing on the matter of the absoluteness of some major prohibitions. In debates over the moral bearings of torture, one of the frequent points of controversy is whether the moral prohibition on torture is absolute. That much-broached question is in need of disambiguation, however (Kramer 2014, pp. 8f). In posing that question, one might be asking whether the duty not to engage in torture is always and everywhere binding in all possible worlds, or one might be asking whether the stringency of that ever-binding duty is always and everywhere greater than the stringency of any duties that might conflict with it. Although an affirmative answer to the latter version of the question entails an affirmative answer to the former version, there is no entailment between affirmative answers in the other direction. Strong absoluteness entails weak absoluteness, but not vice versa.

7 The phrase 'basic moral status' refers to the permissibility or impermissibility of each of the modes of conduct. 
If the moral prohibition on torture is strongly absolute, it is not only binding at all times in all places in all possible worlds; in addition, it is also always more stringent than any possible countervailing moral requirements. One's insistence on the absoluteness of that prohibition in this strong sense is perfectly consistent with one's recognition that there can indeed be countervailing moral requirements that militate against compliance with the prohibition. In other words, a strongly absolute moral obligation can be locked in conflicts with competing moral obligations which are inferior in their normative strength. ${ }^{8}$ Although those latter obligations are indeed less stringent, they impose genuine moral demands that will give rise to remedial duties if they are left unfulfilled. In such circumstances, then, compliance with the strongly absolute moral prohibition is not strongly permissible; it is only weakly permissible.

Any weakly absolute moral prohibition WM is binding everywhere and always in all possible worlds. No circumstances, however exigent, can ever negate or diminish the demands of such a prohibition. Nonetheless, although WM is irrepressibly operative in all possible situations, it can be locked in conflicts with competing moral requirements (just as strongly absolute moral prohibitions can be). Moreover, in some imaginable circumstances, the competing moral requirements are more stringent than WM with which they conflict. In such circumstances, compliance with WM would not be even weakly permissible. There is not available any strongly permissible course of conduct in such a setting, and the sole weakly permissible course of conduct resides in breaching WM. Any such breach is indeed a breach - that is, a moral wrong - and it will thus trigger remedial obligations.

Of course, if WM is formidably stringent, there might never materialize any actual situations in which the contravention of WM would be morally optimal. Nevertheless, so long as there can arise some context in which such a contravention would be optimal, WM is only weakly absolute rather than strongly absolute. Even if conformity to WM is always morally optimal in the actual world, there are never any guarantees of that optimality - for there remain counterfactual scenarios in which some actions at odds with WM are the morally best modes of conduct (the least dreadful modes of conduct).

Now, as has already been suggested, the only absolute that is postulated by consequentialists is a general prohibition on impeding the maximal attainment of some fundamental desideratum or set of desiderata. Any mode of conduct whatsoever that tends toward the fulfillment of such a maximizing goal is

8 This point is altogether missed in Feinberg (1973, p. 86): 'For a human right to have this [absolute] character it would have to be such that no conflicts with other human rights, either of the same or another type, would be possible.' 
strongly permissible by the reckoning of consequentialists. By contrast, many deontologists affirm that certain major moral prohibitions are binding always and everywhere irrespective of the consequences of compliance therewith, and in particular that each of the specified prohibitions is binding even when departures from it will serve to lower greatly the overall frequency with which it is contravened. Insofar as anyone contends that a mode of conduct such as placatory torture is always and everywhere morally wrong, he or she is a deontologist.

\subsubsection{Some transitional remarks}

I have elsewhere argued that placatory torture is morally wrong in all of its possible instantiations (2014, pp. 209ff, 222-30). That absolutist position on the morality of placatory torture is in need of some further defense here, for quite a few philosophers have queried whether deontological absolutism is reconcilable with the requirements of practical rationality. These doubters have in mind especially the agent-centeredness of our duties to refrain from certain acttypes. While granting that those duties are operative in any ordinary contexts, the opponents of deontological constraints insist that the duties would be perverse if they continued to be operative in circumstances where one's undertaking of some normally proscribed conduct can lower the overall incidence of such conduct. That charge of perverseness - amounting to a charge of irrationality - is what the present paper will seek to rebut.

To pose the problem of deontological rationality in its starkest form, this paper will explore a moral conflict that involves an intrapersonal trade-off rather than an interpersonal trade-off. Typically, trade-offs of the former sort are morally far less problematic than trade-offs of the latter sort. Hence, by seeking to establish that the moral prohibition on placatory torture continues to be binding even in the context of an intrapersonal trade-off where a breach of that prohibition would redound to the benefit of the victim of the breach, this paper is deliberately confronting itself with a challenge that leaves no easy routes of escape. Both in its countering of some doubts about the rationality of agent-centered constraints and in its efforts to vindicate the absoluteness of the moral ban on placatory torture, this paper takes the hard and narrow path. It aims to surmount obstacles that are encountered here in their most troublesome guises.

In line with what has just been suggested, the next section of this paper will recount a situation in which the perpetration of placatory torture against a certain victim would lower the incidence and severity of the acts of torture carried out against that very same victim. As will be argued, the perpetration 
of placatory torture is morally wrong even in such a situation. We will then move on to ponder whether the agent-centeredness of deontological duties - such as our duties not to engage in acts of torture - is rationally tenable. Among the philosophers who have impugned the rationality of agent-centered constraints, Samuel Scheffler has mounted a particularly prominent and thought-provoking attack. ${ }^{9}$ He tries to show that agent-centered restrictions clash not only with the tenets of consequentialist moral theories but also with a conception of practical rationality that extends beyond those theories into much of our ordinary thinking about an array of matters. By so arguing, Scheffler presumes to have exposed the unreasonableness of deontological requirements without begging any questions along the way in favor of consequentialist theorizing. Hence, my rebuttal of his influential critique is essential for the sustainment of my contention that placatory torture is always and everywhere morally wrong in all possible worlds. Such torture is morally wrong even when instances of it are undertaken to avert the occurrence of many other instances of wrongful torture.

\section{An intrapersonal trade-off}

In most of the philosophical discussions where deontologists and their opponents contemplate situations in which certain acts of torture will lower the overall incidence of such acts, the trade-offs are interpersonal. That is, some people are to be subjected to torture for the sake of sparing numerous others from comparably dire mistreatment. (Much more often in the scenarios that are broached in these philosophical discussions, the other people are to be spared from sudden death. However, for the purposes of this paper, we need to concentrate on situations in which acts of torture are undertaken to avert the occurrence of other acts of torture that are more numerous or more brutal.) Though scenarios that involve interpersonal trade-offs are illuminating, an investigation of them does not come to grips with the most difficult cruxes that could arise. After all, when a person is to undergo placatory torture in a scenario involving an interpersonal trade-off, we can very easily find a ground for deeming the envisaged use of the torture to be morally wrong. If a person $\mathrm{P}$ is subjected to excruciating pain for the furtherance of the well-being of others, then $\mathrm{P}$ has been used purely as a means for the advancement of the

9 His critique initially appeared as Scheffler (1985), and has then been reprinted as Scheffler (1988) and Scheffler (1994, pp. 133-51). In this paper, my citations are to the (Scheffler 1988) reprinting of his essay. 
ends of those others. Accordingly, the administration of the torture is straightforwardly condemnable on moral grounds, even if it is morally optimal in the circumstances.

Seemingly, one way to keep the endeavor of moral condemnation from being too easy is to tweak the thought-experiment by adding to it the factor of consent. If the victim of the torture has consented to undergoing it in order to save some other people from being afflicted with agonizing pain, then the subjection of her to the torture might appear to be classifiable as one of her projects - in which case she is not being treated solely as a means for the furtherance of others' ends during that subjection. However, the provision of consent under conditions of extreme duress does not significantly alter the moral character of the situation. Sincere and selfless though the consent may very well be, it is tendered under conditions that deprive it of full efficacy. The legitimizing force bestowed by consent in most ordinary circumstances is not bestowed by the coerced consent of a person who braves torture in order to spare other people from a similar fate. Her preparedness to sacrifice her own well-being for theirs does ethically alter some aspects of the situation, but it does not alter the fundamental moral status of the torture from impermissible to permissible.

In short, when a thought-experiment involving the use of torture for the purpose of placation is amplified in a way that retains the interpersonal structure of the depicted trade-off, it does not really pose a stiff challenge to an absolutist position on the morality of torture. Detecting the wrongness of the torture administered in such a scenario is not a very difficult feat. Let us, then, probe a more formidable example that replaces the interpersonal trade-off with an intrapersonal trade-off.

\subsection{Melvin and Miranda}

Fifteen thugs burst into the house of Melvin and Miranda one evening. Several of them tie Miranda firmly to a plinth on which they have splayed her. Brandishing guns and explosives, the thugs order Melvin to subject Miranda to torture by applying some lighted cigarettes and an electric-shock device to sensitive parts of her body repeatedly. They admonish Melvin that, if he shrinks from this ghastly assignment, they themselves will apply those methods of torture to Miranda's body far more protractedly along with several other methods of torture that are even more excruciating. Melvin is faced with a stark choice, then. Either he subjects his wife to torture himself or he lets her be subjected to a considerably harsher ordeal of torture by the thugs. (In the event of his noncompliance with 
their behests, he will be securely restrained by several of the thugs while some of their comrades administer the torture to Miranda's body.)

Although Melvin of course will harbor some uncertainty concerning the thugs' intentions, his epistemic situation is not racked with doubts. He knows that the thugs have carried out a number of similar raids on the homes of married couples in various parts of the country. On each occasion when a husband has engaged in the terrible acts of torture which he has been ordered to perform, the thugs have then left the premises without further ado. Contrariwise, on each occasion when a husband has refused to do what the thugs have directed him to do, they have fulfilled their threat by applying torture prolongedly and savagely to his wife. Melvin knows these facts, which have been reported widely in the news media over the months when these atrocious incidents have taken place. He is therefore confident - not absolutely certain, of course, but confident - that the thugs mean just what they say when they bid him to torture Miranda in order to spare her from an even more hellish process of mistreatment at their hands.

Miranda likewise knows about the past raids conducted by the thugs, and therefore she too is confident that her tormentors mean exactly what they say. She consequently urges her husband to obey their behests. She hardly relishes the prospect of being afflicted with severe pain by the acts of burning and shocking to which he will have to stoop, but she wants to avoid the grimmer ordeal that will be inflicted on her if Melvin declines to perform those repellent acts. She recognizes that he is filled with revulsion at the thought of torturing her, but she implores him to overcome that revulsion. With huge reluctance and consternation, Melvin heeds her entreaties.

\subsection{The significance of the thought-experiment}

Although this tale of Melvin and Miranda is in many respects similar to Alan Gewirth's famous scenario of a politician who is commanded by terrorists to torture his own mother (1981), one key difference is that Melvin has undertaken the placatory torture not with the aim of saving the lives of numerous other people but instead with the aim of minimizing the agony that will be inflicted on Miranda. The harrowing trade-off is intrapersonal rather than interpersonal. As a result, a vindication of my absolutist position on the wrongness of placatory torture cannot rest content with Robert Nozick's account of the inviolability of individuals:

Side constraints [that is, deontological duties] express the inviolability of ... persons. But why may not one violate persons for the greater social good? Individually, we each 
sometimes choose to undergo some pain or sacrifice for a greater benefit or to avoid a greater harm: we go to the dentist to avoid worse suffering later; we do some unpleasant work for its results; some persons diet to improve their health or looks; some save money to support themselves when they are older. In each case, some cost is borne for the sake of the greater overall good. Why not, similarly, hold that some persons have to bear some costs that benefit other persons more, for the sake of the overall social good? But there is no social entity with a good that undergoes some sacrifice for its own good. There are only individual people, different individual people, with their own individual lives. Using one of these people for the benefit of others, uses him and benefits the others. Nothing more. What happens is that something is done to him for the sake of others. Talk of an overall social good covers this up. (Intentionally?) To use a person in this way does not sufficiently respect and take account of the fact that he is a separate person, that his is the only life he has. He does not get some overbalancing good from his sacrifice. ${ }^{10}$

Nozick's remarks on inviolability are fine as far as they go, but his appeal to inviolability does not go far enough. For one thing, as I have argued elsewhere (2014, pp. 187f.; 2017, pp. 262f.), a focus on inviolability will leave us unable to explain why heinous wrongdoers such as Khalid Sheikh Mohammed cannot ever legitimately be subjected to interrogational torture or punitive torture. Much more important in the present context is that Nozick's reflections on inviolability powerful though they are - do not settle the matter of coerced intrapersonal tradeoffs. That is, they do not settle the question whether someone can legitimately be mistreated to spare her from even worse mistreatment. What makes the scenario of Melvin and Miranda problematic is its posing of that very question.

In one respect, of course, the situation limned in my tale of Melvin and Miranda is morally clear-cut. Any sensible person would agree that the actions of the thugs are morally reprehensible. However, the interesting question about the situation obviously pertains not to their actions but to the actions of Melvin.

10 Nozick (1974, pp. 32f., footnote omitted, emphases in original). My narrative of Melvin and Miranda differs not only from Gewirth's and Nozick's examples, but also from Bernard Williams's famous scenario of Jim and the Indians. See Williams (1973, pp. 98f). Williams envisaged a situation in which twenty Indians are about to be slain summarily. A traveler who comes upon the scene is presented with an opportunity to save the lives of nineteen of the Indians by killing the one remaining member of their group. Though the one Indian will not be made worse off by the traveler's act of slaying him (since he would have been shot in any event), he will likewise not be made any better off by that act.

Of course, in one respect, the trade-off in my scenario of Melvin and Miranda is interpersonal rather than intrapersonal. That is, it involves conduct performed by Melvin in relation to Miranda. In such a respect, the trade-off here is different from that of a person who restricts her own intake of food for the purpose of becoming slimmer. However, the trade-off in my scenario is intrapersonal in the respect that is central to Nozick's reflections. That is, the person who is to be spared from mistreatment by Melvin's conduct is the same as the person who is to be subjected to mistreatment by his conduct. 
Has he behaved permissibly when he resorts to torturing his wife in the dire circumstances? Has he behaved permissibly by complying with her own expostulations as well as with the bidding of the thugs?

\subsubsection{The factor of consent}

Although Miranda has consented to being tortured by Melvin, her consent is not fully efficacious. Her consent is of course wholeheartedly sincere and indeed desperately exhortative, but it is provided under conditions of overwhelming duress. Its efficacy is largely vitiated by its coercedness. Hence, the permissibility-engendering effect produced in many circumstances by consent is not produced by Miranda's impetrations; the extreme coercion under which the victim gives her consent is destructive of any legitimizing force which the consent might otherwise have possessed.

That destructive upshot of the coercion is independent of the distinction between an interpersonal trade-off and an intrapersonal trade-off. Notwithstanding that Miranda furnishes her consent for her own good whereas the mother in an amplified version of Gewirth's scenario furnishes her consent for the good of others, Miranda's consent does not confer permissibility on Melvin's acts of torture any more than the mother's consent would confer permissibility on the politician's acts of torture. Though the intrapersonal/interpersonal distinction might make a moral difference in some other respects, it does not here make a moral difference with regard to the factor of consent. The legitimacy-engendering effect of any instance of consent depends both on the voluntariness of the consent and on the legitimacy of the purpose for which the consent has been tendered. While Miranda's purpose of sparing herself from additional agony (through an intrapersonal trade-off) and the mother's purpose of saving other people's lives (through an interpersonal trade-off) are both legitimate, the consent in each case is deprived of its voluntariness by the terrible and credible threats to which it is a response. In neither case, then, does the consent render morally permissible the use of placatory torture.

Still, although Miranda's fervent exhortations to Melvin do not alter the basic moral status of his acts of torture from impermissible to permissible, they do mitigate the gravity of the wrongness of those acts. Whereas Miranda's remonstrations would be bizarrely unreasonable in any ordinary circumstances, they are quite understandable in the appalling predicament in which they are uttered. Hence, when Melvin proceeds in accordance with those remonstrations, he is fulfilling some earnestly expressed wishes of his wife that are reasonable in the circumstances. In that respect, his outlook is very different from that of a 
typical torturer. Though the coercedness of Miranda's expressions of her wishes is enough to deprive them of any legitimizing force, it does not deprive them of extenuative force. The fact that Melvin does what his wife desperately and understandably wants him to do is a consideration that manifestly lessens the culpability of the wrong which he has to commit against her.

\subsubsection{The orientation of the torture}

The torture administered by the politician to his mother in Gewirth's scenario is inimical to the mother's bodily and psychological well-being. Were the torture not to take place, the mother would be much better off (except in her distress over the harm inflicted on other people by the explosions which the terrorists would detonate in response). Less straightforwardly classifiable is the orientation of the torture undertaken by Melvin against Miranda; here the problem of fixing upon the germane baseline of comparison looms large.

On the one hand, when we ask whether Miranda will be better off if Melvin declines to perform any acts of torture, the answer is negative. Given that the thugs are resolutely disposed to perpetrate far worse acts of torture against her in the event of Melvin's noncompliance with their behests, his engaging in placatory torture redounds to the benefit of her bodily and mental well-being. Injurious to her though his acts of burning and shocking are, they forestall the considerably worse onslaughts that would have been inflicted by the thugs in response to his defiance of their orders. Thus, if the appropriate baseline of comparison is the course of events that would have unfolded in the presence of such defiance, the orientation of Melvin's placatory torture toward Miranda's physical and psychological welfare is benevolent.

On the other hand, if the appropriate baseline of comparison is instead a course of events in which nobody contravenes the moral prohibition on the perpetration of torture against Miranda, the acts of placatory torture by her husband make her considerably worse off. The exquisite pain and wounds caused by his acts of burning and shocking are obviously detrimental to her elementary well-being, if they are compared with the absence of any such untoward effects in the moralized baseline course of events that has just been broached. Because his acts of torture foreseeably cause such deleterious effects, the orientation of his conduct toward Miranda's bodily and mental soundness is destructive rather than benignly supportive. Of course, Melvin engages in those acts not with relish but with the utmost repugnance. Still, the impact of his torturous techniques on Miranda - in comparison with the morally required situation in which no one afflicts her with any such techniques - is severely harmful. 
Now, if our moral assessment of Melvin's behavior is to be well-founded, we need to take account of the full array of circumstances in which the behavior has occurred. Given as much, the appropriate baseline of comparison for judging the harmfulness of his actions is the first rather than the second. The context in which Melvin resorts to torture is not the morally required situation in which everyone else is disposed to abstain from any torturous measures; he adopts his harrowing course of conduct precisely in recognition of that fact. Faced with a plight in which he cannot keep Miranda from undergoing agony, he does his best to minimize the harm and pain that will be inflicted on her - even though the only tack open to him that will produce such a result is the subjection of her to torture. In the dreadful circumstances, the orientation of his placatory torture toward her bodily and mental well-being is benevolent.

\subsubsection{Perpetrator-focused reflections}

So far, I have adopted a victim-focused perspective by concentrating on the interests and autonomy of Miranda as the decisive factors for gauging whether the torture administered to her by Melvin is morally wrong. That is, I have heretofore asked whether her interests are furthered or set back by Melvin's actions and whether her autonomy is respected or flouted by those actions. Although the victim-focused considerations that we have pondered are somewhat inconclusive, they largely militate in favor of the proposition that Melvin's recourse to placatory torture is morally legitimate. Miranda has not uncoercedly consented to the torture, but she has fervently consented in a context in which no uncoerced consent is possible. Notwithstanding that the burning and shocking of her body by Melvin will greatly impair her welfare, the orientation of those measures is benevolent in light of the horrific harm which they fend off. Hence, even though the victim-focused considerations are not entirely clear-cut, they do not on the whole supply a basis for deeming Melvin's actions to be wrong.

However, if we are to assess the morality of Melvin's placatory torture fully, the victim-focused perspective has to be supplemented by a perpetratorfocused perspective. In other words, we have to attend not only to the interests and dignity of Miranda but also to the integrity or probity of Melvin. ${ }^{11}$ From such a perpetrator-focused perspective, we can descry the wrongness of Melvin's resort to placatory torture. Though Melvin is desperately well-intentioned as he takes the steps that are necessary to spare his wife from the

11 For much longer treatments of the distinction between a victim-focused perspective and a perpetrator-focused perspective, see Kramer (2014, pp. 187-212; 2017, pp. 142ff, 254-64). 
viciousness of the thugs, he morally degrades himself by taking those steps. From a perpetrator-focused perspective, we can see that his conduct is fundamentally on a par with the conduct of the politician in Gewirth's scenario. Melvin uses himself and Miranda as playthings of the thugs, as he shows himself ready - however reluctantly and disconsolately - to stoop to an especially demeaning and terrible mode of conduct for the sake of keeping the thugs at bay. Albeit his conduct is in conformity to his wife's entreaties, the only people whose uncoerced wishes he obeys are the thugs. They gleefully want Miranda to be tortured, and they particularly want Melvin to administer the torture. When he abases himself by submitting to their directives, he is ignominiously providing them with exactly what they desire. He has been forced by them into becoming an active participant in his own psychological humiliation and moral degradation, as he turns his agency into the vehicle through which the thugs afflict Miranda with excruciating pain. He indelibly stains the relationship between himself and his wife, as he subjects her to modes of mistreatment to which nobody can ever legitimately be subjected (outside certain contexts in which soldiers or spies undergo training for endurance). Though Melvin and Miranda might recover from their ordeal psychologically and physically, the ethical tenor of their relationship will henceforward be tarnished by his demonstration of his willingness to afflict her with such mistreatment. He has shown that he is prepared to place his agency in the service of the thugs as an instrument of their torturous designs - designs that are centered on debasing him as just such an instrument.

\subsubsection{Moral optimality}

By resorting to placatory torture, Melvin has sullied his moral integrity and his relationship with his wife. Albeit the inconclusive victim-focused considerations pertaining to the torture are not in themselves sufficient to deprive it of moral legitimacy, the perpetrator-focused considerations just outlined do indeed render Melvin's conduct morally wrong. His conduct breaches a duty owed to himself and a duty owed to Miranda; the former duty requires Melvin to sustain the conditions for a warrantedly high level of self-respect, while the latter duty requires him to abstain from gross forms of mistreatment. However, although his torturous actions are not strongly permissible, they are weakly permissible. That is, in the grim predicament in which Melvin performs those actions, they are morally optimal. His having recoiled altogether from performing them would have been an even graver wrong than his having performed them. 
Melvin has owed and contravened the moral duties mentioned above, but those are not the only moral duties that are incumbent on him in his plight. He owes a duty to Miranda to take all feasible and necessary steps to defend her against any foreseeable infliction of very serious harm. ${ }^{12}$ In the grotesque circumstances, the only way in which he can discharge that duty is to subject her to placatory torture. He will thereby be causing severe harm to her, of course, but he will be protecting her from the even worse harm that she would have undergone at the hands of the thugs directly. Moreover, his recourse to placatory torture occurs not least as a response to her own supplications. If she had not urged him to accede to the behests of the thugs - and especially if she had adjured him to preserve his moral integrity and the integrity of their relationship by refusing to treat the two of them as playthings for the amusement and mollification of the thugs - his recourse to torture would not have been morally optimal. It would not have been even weakly permissible (though its gravity would still have been considerably mitigated by the horrific context of its occurrence). However, given that Miranda has in fact beseeched Melvin to overcome his scruples in order to lessen her misery, his torturous actions are morally optimal. While running athwart some stringent moral duties that continue to be binding upon him, his actions fulfill some even more stringent moral obligations that are in conflict with the duties which he has breached.

Although the moral optimality of Melvin's conduct does not render that conduct morally legitimate, it does markedly attenuate the gravity of the wrongs that Melvin has committed. He has wronged both himself and Miranda, but - given the full circumstances, including her robust expostulations - his declining to carry out the placatory torture would have wronged her even more severely. In a terrible quandary that has confronted him with a choice between two morally impermissible courses of conduct, he has chosen correctly (even though his correct choice has not enabled him to avoid the commission of some wrongs). Consequently, the remedies morally required of him in the aftermath of his actions will be relatively mild. In particular, he should not be subjected to any criminal sanctions or other legal sanctions. If he is ever brought to trial on any criminal charges for his wielding of torturous measures against Miranda, he should be acquitted with a full excuse of duress.

12 She owes him a cognate duty, of course, though no steps are feasible for her after the thugs have tied her securely to the plinth. 


\section{Are deontological constraints irrationally demanding?}

In the thought-experiment relating to Melvin and Miranda, as in any other setting where deontological constraints are applicable, the moral permissibility or impermissibility of someone's conduct is not determined by any consequentialist balance of considerations. More specifically, the fact that a person can lower the overall incidence of some dreadful mode of conduct by engaging in that mode of conduct is not something that renders morally legitimate his choice to engage in it. Melvin perpetrates acts of torture against Miranda in order to keep her from being subjected to even worse acts of torture. By any genuinely consequentialist reckoning, then, his conduct is impeccable. ${ }^{13}$ Under any such reckoning, his behavior is not only morally optimal but also strongly permissible. Though the considerations which he acts against (considerations such as his own moral integrity) are classifiable as desiderata by some consequentialist theories, they are not classifiable as absolute constraints. His acting against those considerations will lead some consequentialists to regard his behavior as regrettable or costly in certain respects, but not as morally impermissible in any respect. By contrast, a deontological theorist can recognize that the moral impermissibility of placatory torture is consequence-independent. Irrespective of the fact that Melvin can lower the overall number of acts of torture against Miranda by performing such acts, his resorting to any such measures is morally illegitimate. He wrongs both himself and Miranda when he burns and shocks her, even though the trade-off which he thereby accomplishes is intrapersonal rather than interpersonal. His recourse to placatory torture is morally optimal but not strongly permissible.

My scenario of Melvin and Miranda thus raises, in an especially acute form, a problem that has troubled many proponents and critics of deontological doctrines. Is the agent-centeredness of deontological constraints at odds with practical rationality? How can acts of torture be morally wrong if they foreseeably avert some far more numerous and brutal acts of torture that would otherwise have taken place? To philosophers of a consequentialist bent, any such ascription of moral wrongness seems irrational. These philosophers do not fathom how we can ever be morally required to bring about states

13 I am assuming here that, if a rule-consequentialist theory is to be a genuinely consequentialist doctrine (rather than a misleadingly packaged deontological theory), any precept laid down by it against the use of placatory torture will have to allow for exceptions in cases like that of Melvin and Miranda. 
of affairs that are worse (perhaps far worse) than the states of affairs that we would foreseeably bring about by acting contrary to the terms of deontological restrictions. Their doubts about the rationality of deontological prohibitions will be particularly intense with regard to situations which relevantly resemble that of Melvin and Miranda. How can Melvin be under a moral obligation to abstain from perpetrating any placatory torture against Miranda, given that his abstention from the placatory course of action will foreseeably lead to a state of affairs that is far worse for her (as well as worse more generally) than the state of affairs that will be brought about through his perpetration of the torture? In the eyes of consequentialists, such an obligation is perverse and is therefore morally unsustainable.

\subsection{Rationality and maximization}

These consequentialist worries about the irrationality of deontological constraints have been voiced with trenchancy by Scheffler, who asks:

[H]ow can it be rational to forbid the performance of a morally objectionable action that would [foreseeably] have the effect of minimizing the total number of comparably objectionable actions that were performed and would have no other morally relevant consequences? How can the minimization of morally objectionable conduct be morally unacceptable ${ }^{14}$

He endeavors to parlay these queries into a general critique of deontology by maintaining that agent-centered limits on the maximizing of good consequences or the minimizing of bad consequences run counter to demands of practical rationality that are widely and deeply embraced. He believes that, because those demands are routinely recognized as such in a myriad of contexts, the invocation of them against deontological doctrines does not damagingly beg any questions in favor of consequentialism. He writes:

[A]lthough the conception of rationality that generates the appearance of paradox [in deontology] lies at the heart of consequentialism, it is not peculiar to consequentialism. On the contrary, it is a fundamental and familiar conception of rationality that we accept and operate with in a very wide and varied range of contexts.

14 Scheffler (1988, p. 244). My insertion of the adverb 'foreseeably' does not perforce align me with consequentialists who insist that foreseeable consequences rather than actual consequences are decisive in the pursuit of any maximand. Rather, my insertion is aimed at shoring up Scheffler's query by shielding it against an obvious objection that might be posed by such consequentialists. 
Claiming as much, Scheffler thus contends that the allure of consequentialism an allure which, according to him, is felt by all or most opponents of consequentialism as well as by its champions - 'derives from the fact that it appears to embody a notion of rationality which we recognized from myriad diverse contexts, and whose power we have good independent reason to respect' (1988, p. 251).

Scheffler proceeds to recount the nature of the rationality which he perceives as central to multitudinous everyday practices as well as to consequentialism:

The kind of rationality that consequentialism seems so clearly to embody, and which makes so much trouble for views that incorporate agent-centered restrictions, is what we may call maximizing rationality. The core of this conception of rationality is the idea that if one accepts the desirability of a certain goal being achieved, and if one has a choice between two options, one of which is certain to accomplish the goal better than the other, then it is, ceteris paribus, rational to choose the former over the latter. Consequentialism seems to embody this kind of rationality because it starts from a conception of what is desirable (the overall good) and then tells us always to promote as much of it as we can. (1988, p. 252, emphasis in original)

In anticipation of my rejoinders to Scheffler's critique of deontology, we should here glancingly note two points. First, Scheffler does not adduce any evidence to substantiate his repeated assertions that the maximizing conception of rationality is operative in a vast medley of quotidian contexts. That omission is significant, for - as I will contend later - there are strong grounds for doubting that that conception in any unrestricted form is indeed widely operative in everyday settings. Second, if the 'ceteris paribus' clause in the extract above were to be construed expansively, it would leave ample room for a reconciliation between deontological restrictions and the maximizing conception of rationality. Scheffler recognizes as much, and he therefore goes on to argue that the 'ceteris paribus' clause cannot properly be invoked to effect such a reconciliation. I will impugn his argument on that point in due course.

\subsection{Deontological commitments}

In some ruminations which this paper will scrutinize shortly, Scheffler explores the inconsistency between deontological constraints and the maximizing conception of rationality. However, before we probe those ruminations, we should take note of his contention that deontologists themselves are committed to that conception of rationality. His main explanation of their being so committed is contained in the following passage: 
[Deontological doctrines] seem committed to the idea that violations of [agent-centered] restrictions are morally objectionable or undesirable, in the sense that there is a moral point of view from which it is preferable that no violations should occur than that any should. Defenders of deontological views are typically happy to say things like this, and with good reason. For on standard deontological views, morality evaluates actions from a vantage-point which is concerned with more than just the interests of the individual agent. In other words, an action will be right or wrong, on such a view, relative to a standard of assessment that takes into account a number of factors quite independent of the interests of the agent. And defenders of such views are unlikely to claim that the relevant standard of assessment includes agent-centered restrictions, but that it is a matter of indifference, from the vantage-point represented by that standard, whether or not those restrictions are violated. For if it is not the case that it is preferable, from that vantage-point, that no violations should occur than that any should, it is hard to see how individual agents could possibly be thought to have reason to observe the restrictions when doing so did not happen to coincide with their own interests or the interests of those they cared about. In other words, deontological views need the idea that violations of the restrictions are morally objectionable or undesirable if the claim that people ought not to commit such violations when doing so would be in their own interests is to be plausible. (1988, pp. 253f, emphasis in original)

Now, on the one hand, proponents of deontological doctrines will tend to be wary of the language in this latest extract. Scheffler inappositely conveys the impression that those doctrines are centered on evaluations of states of affairs. On the other hand, the gist of what is said in the extract is unexceptionable provided that it is amplified or qualified in one respect.

Although deontologists rightly insist that every contravention of a deontological prohibition is morally wrong, they are not quite committed to the proposition that it is always better that no contraventions occur than that any do. Suppose for example that Edgar, who is a meteorologist or a seismologist, has to break a promise in order to take some steps that are necessary to avert a natural disaster. If we compare a situation in which Edgar keeps his promise and a situation in which he averts the disaster by departing from his promise, we are comparing a course of events in which no transgressions of deontological prohibitions occur and a course of events in which at least one such transgression occurs. (As a product of meteorological or seismic developments, the natural disaster would not consist in any contraventions of deontological restrictions if it were to proceed.) Deontologists should nonetheless allow that, because the consequentialist considerations in favor of Edgar's taking the steps necessary to avert the catastrophe are extremely weighty, his breaking of his promise in order to take those steps is morally optimal. To be sure, his breach of his promise is morally wrong; it is only weakly permissible rather than strongly permissible, and it therefore places him under a moral obligation to apologize to the promisee or to undertake some other suitable remedial measure. Still, the wrongness of the non-fulfillment of the 
promise is entirely consistent with the moral optimality of such a course of conduct - and it is indeed a morally optimal course of conduct in the circumstances. Recognizing as much, deontological absolutists are not quite committed to the proposition that it is always better that no contraventions of deontological prohibitions occur than that any do.

Many other examples could be adduced, not all of which would involve the prevention of natural disasters. When a deontological obligation (such as a minor promissory obligation) is not formidably stringent, and when a breach of that obligation can avert a very substantial detriment or produce a very substantial benefit, and when the non-occurrence of the breach would not involve any contraventions of deontological duties, the situation can be such that a breach of a deontological obligation - despite its wrongness - is better in the circumstances than no such breaches at all. Still, Scheffler obviously does not have in mind quandaries of that kind. If we prescind from such quandaries, and if we think instead only of predicaments in which noncompliance with deontological constraints is necessary for the prevention of some even more numerous or even more serious instances of noncompliance, then the passage quoted above is correct in its account of one of the commitments of deontologists. Within the confines just indicated, deontologists are indeed committed to the proposition that it is always better that no transgressions of deontological prohibitions occur than that any do. Let us designate that proposition as the 'No Contraventions Principle'. My ripostes to Scheffler's critique of deontology will henceforth endorse the No Contraventions Principle and will not mention again the requisite qualification discussed in this paragraph and the preceding paragraph. (Any further mention of that qualification would be gratuitous, since it will play no role in my rebuttal of Scheffler's critique.)

\subsection{Slippage from none-versus-any to fewer-versus-more}

The fatal misstep that undoes Scheffler's critique of deontology is his recurrent shifting from the No Contraventions Principle - a principle focused on the distinction between no transgressions of deontological prohibitions and some such transgressions - to a quite different thesis about the distinction between fewer transgressions and more. That latter thesis, which can be designated here as the 'Minimization Principle', consists in the claim that it is always morally permissible for someone to act in a way that will foreseeably bring about fewer violations of some deontological restriction(s) than would his or her abstention from so acting. Unlike the No Contraventions Principle, the Minimization Principle is a thesis which every deontologist would and should reject. 


\subsubsection{A first example of the conflation}

Scheffler's conflation of the none-versus-any duality and the fewer-versus-more duality is first occurrent in his exposition of the maximizing conception of rationality:

Views that incorporate agent-centered restrictions ... seem troubling, relative to this [maximizing] notion of rationality. For they appear to identify certain kinds of actions as morally objectionable or undesirable, in the sense that it is morally preferable that no such actions should occur than that any should, but then tell us that there are situations in which we must act in such a way that a greater rather than a lesser number of these actions are actually performed. (1988, p. 252)

In the closing portion of this quotation, the auxiliary verb 'must' is clearly to be construed as deontic. Hence, the quoted remark is composed of three main claims. First, the opening sentence correctly maintains that agent-centered restrictions are at odds with the maximizing conception of rationality which Scheffler expounds. Second, the initial half of the next sentence rightly asserts that deontologists embrace the No Contraventions Principle. Third, the closing portion of that next sentence accurately indicates that deontologists reject the Minimization Principle.

In other words, each of the three main claims in the quotation is unexceptionable. What is puzzling is Scheffler's assumption - signaled by 'but' in the second sentence of the quotation - that deontologists' embrace of the No Contraventions Principle is in tension with their rejection of the Minimization Principle. His perception of some tension derives from his conflation of the noneversus-any contrast and the fewer-versus-more contrast, for the No Contraventions Principle pertains to the former contrast whereas the Minimization Principle pertains to the latter.

Suppose that, instead of adhering to the No Contraventions Principle, deontologists adhered to a variant of that principle focused on the fewer-versus-more dichotomy. That is, suppose they were committed to the thesis that it is always morally better that a smaller number of violations of deontological prohibitions occur than that a greater number occur. In that event, their position concerning what is always morally better would be in tension with their repudiation of the Minimization Principle. In fact, however, deontologists are not committed to the smaller-versus-greater thesis that has just been broached. They are instead committed to the No Contraventions Principle, which Scheffler accurately attributes to them at many junctures. Given as much, there is not even a superficial contrariety between their position concerning what is always morally better and their repudiation of the Minimization Principle. 
Deontologists reject the Minimization Principle because it implies that contraventions of deontological prohibitions are sometimes morally permissible. Their position on that point is straightforwardly consistent with their endorsement of the No Contraventions Principle. After all, in any situation with reference to which the Minimization Principle would deem a transgression of a deontological prohibition to be morally permissible for some person $\mathrm{P}$, the non-scalar ideal encapsulated in the No Contraventions Principle cannot be realized through any mode of conduct available to P. Thus, when deontologists reject the implications of the Minimization Principle in regard to any such situation - and when they thereby insist that $\mathrm{P}$ is morally obligated in the specified circumstances to behave in a way that will result overall in more rather than fewer violations of deontological constraints - there is not the slightest tension with their espousal of the No Contraventions Principle. The No Contraventions Principle does not draw a favorable comparison between fewer violations and more; rather, it draws a favorable comparison between no violations and some. It articulates the underlying attitude not of a person who minimizes violations, but of a person who eschews them.

\subsubsection{A second example}

Scheffler again rides roughshod over the distinction between the none-versussome dichotomy and the fewer-versus-more dichotomy, in the following passage:

Yet if [deontological] views do regard violations [of deontological restrictions] as morally objectionable or undesirable, in the sense that it is morally preferable that none should occur than that any should, it does then seem paradoxical that they tell us there are times when we must act in such a way that a larger rather than a smaller number of violations actually takes place. (1988, p. 254)

This passage declares that deontologists are adopting a paradoxical set of positions when they embrace the No Contraventions Principle while gainsaying the Minimization Principle. As should be evident from my response to Scheffler in the preceding subsection, however, the deontologists' combination of positions is not paradoxical at all. On the contrary, because the No Contraventions Principle encapsulates the underlying attitude of someone who seeks to avoid any violations of deontological constraints - rather than the underlying attitude of someone who seeks to minimize such violations - one's endorsement of that principle goes together very smoothly with one's rejection of the Minimization Principle. Only by eliding the difference between the none-versus-some contrast and the fewer-versus-more contrast has Scheffler presumed to find any incongruity between the positions which the deontologists combine. 


\subsubsection{Goals for deontologists: a first example}

Writing more than a decade after Nozick inveighed against any efforts to formulate deontological doctrines in terms of goals, Scheffler nonetheless contends that the proponents of those doctrines cannot overcome the following problem:

[V]iews incorporating agent-centered restrictions actually do present as desirable [a] goal whose maximum accomplishment they then prohibit. They assign each person the agentrelative goal of not violating any restrictions himself ... .Thus in forbidding the minimization of overall violations, they are ... thwarting the achievement of [a] goal whose desirability they recognize. (1988, p. 254)

He slightly later reaffirms that

defenders of standard deontological views do not appear to be in a position to make the claim that, in forbidding us to minimize the violations of those restrictions they insist on, they are not thwarting the achievement of any goal whose desirability they recognize (1988, p. 255).

Despite Nozick's apt animadversions on the use of teleological language in the formulation of deontological constraints, we can accept as harmless the notion that a deontological theory assigns to each person the agent-centered goal of not contravening any deontological restrictions. That goal is strictly non-scalar; the attainment of it is an all-or-nothing matter. What is remarkable in Scheffler's comments is the suggestion that the realization of that nonscalar goal is undermined by the deontologists' rebuffal of the Minimization Principle. On the contrary, any transgression of a deontological constraint DC that is undertaken by someone to lower the overall incidence of transgressions of DC will ensure that he or she fails to achieve the goal of not contravening any deontological restrictions. Only by avoiding all such transgressions can he or she attain that goal.

Immanent in the No Contraventions Principle is the overarching ideal of thorough compliance by everyone with deontological prohibitions. Let us designate that agent-neutral ideal - an ideal to which deontologists are genuinely committed - as the 'Thorough Compliance Objective'. Such an ideal will go unfulfilled in any situation where some person P breaches DC in order to avert some other violations of DC. The Thorough Compliance Objective does not call for a minimized level of contraventions of DC. Rather, it calls for no contraventions of DC; it is focused on the contrast between none and some rather than on the contrast between fewer and more. Hence, the realization of the Thorough Compliance Objective is stymied whenever $\mathrm{P}$ strives to minimize the level of transgressions of DC by engaging in a transgression. 
Of course, the Thorough Compliance Objective will also go unfulfilled if $\mathrm{P}$ refrains from breaching DC and thereby allows some other breaches of DC to occur. My point is not that that agent-neutral ideal will always be given effect by P's attainment of the agent-centered goal of avoiding any breaches of DC. My point, rather, is that P's attainment of that latter goal is a necessary condition for the fulfillment of the agent-neutral ideal. Whenever $\mathrm{P}$ deviates from his agent-centered goal - even if his aim is to increase the overall level of conformity to DC - he thwarts the realization of the Thorough Compliance Objective.

Perhaps, when Scheffler refers to a goal thwarted by deontologists, he has in mind neither the agent-centered goal of avoiding any transgressions of DC nor the agent-neutral Thorough Compliance Objective. Perhaps he instead has in mind the agent-neutral goal of minimizing the number of transgressions of DC. If so, he is correct in maintaining that the achievement of that agent-neutral goal can sometimes be thwarted by one's pursuit of the agent-centered goal of not acting at odds with DC. However, we should then be baffled by Scheffler's assertion that deontologists are somehow committed to recognizing the desirability of the accomplishment of the minimizing goal. Deontologists are not committed in any way to being consequentialists. The only agent-neutral ideal that can accurately be ascribed to them - an ideal repeatedly ascribed to them by Scheffler himself - is the Thorough Compliance Objective. That ideal is not a minimizing goal; it is centered on the division between no contraventions and some, rather than on the division between fewer contraventions and more.

In the first of the two quotations at the outset of this subsection, Scheffler speaks of a 'goal whose maximum accomplishment [deontological doctrines] then prohibit.' Similarly, he later states that 'deontology is [committed] to presenting as desirable [a] non-relative goal whose maximum accomplishment it then prohibits' (1988, p. 254). Given these references to the maximum accomplishment of a goal, and given that the goal of minimizing the number of violations of DC is itself non-scalar, Scheffler here presumably has in mind the goal of lowering the number of the violations. That latter goal is scalar; the maximum accomplishment of it would consist in minimizing the incidence of violations of DC. Again, however, Scheffler is quite mistaken in claiming that deontologists are committed to holding that the fulfillment of a consequentialist goal of the sort just mentioned is desirable. Though deontologists will undoubtedly accept that the realization of such a goal is desirable within the constraints of any deontological prohibitions, they are certainly not committed to accepting that the realization of such a goal is desirable even when it requires some breaches of those prohibitions. As has been stated, the only agent-neutral ideal which deontologists are committed to embracing is the Thorough 
Compliance Objective. That non-scalar ideal consists in no violations of DC rather than in a lowered level of violations.

\subsubsection{Goals for deontologists: a second example}

I have already remarked that the 'ceteris paribus' clause in Scheffler's exposition of the maximizing conception of rationality could be an opening for a reconciliation between that conception and the requirements of deontology. Scheffler seeks to close off that opening, in the following passage where he again attributes to deontologists a teleological outlook (1988, p. 256f):

[S]omeone who wanted to show that there was no conflict between agent-centered restrictions and maximizing rationality might point out that, if the ceteris paribus clause in the formulation of maximizing rationality were fully cashed out, one of its main features would be a provision to the effect that it can sometimes be rational to act in such a way as to worse achieve one goal if that will make it possible to better achieve another. Since that is so, it might be said, views that include agent-centered restrictions need not come into conflict with maximizing rationality when they tell us to further the agent-relative goal of not violating the restrictions ourselves at the expense of the non-relative goal of minimizing violations of the restrictions. By itself, however, this claim is not fully persuasive. The problem is that the agent-relative goal and the non-relative goal appear to be related to each other in such a way as to make the insistence on giving priority to the relative goal puzzling, from the standpoint of maximizing rationality. Since, as our earlier discussion suggested, the fact that violations of the restrictions are objectionable from a moral point of view constitutes at least part of the basis for claiming that individual agents ought not ordinarily to commit such violations, the agent-relative goal looks as if it is derivative from, and given life by, the non-relative objection, and does not appear to represent something independently desirable. Rather, the desirability of achieving the agent-relative goal seems contingent on its serving to advance the non-relative goal of minimizing the morally objectionable. And if that is so, then the insistence that one must satisfy the agent-relative goal even when doing so will inhibit achievement of the non-relative goal is incompatible with considerations of maximization.

In many respects, the most revealing word used here by Scheffler is 'ordinarily' in the antepenultimate sentence of this passage. Whereas consequentialists maintain that individual agents ordinarily ought not to transgress deontological restrictions - because conformity to those restrictions is ordinarily promotive of good consequences - deontological absolutists insist that individual agents ought not to transgress deontological restrictions, tout court. There is no 'ordinarily' qualification in what the deontological absolutists claim about the requisiteness of abiding by deontological constraints. Once the unqualified nature of any deontological constraints is duly recognized, they do not at all appear to be 
derivative of the goal of minimizing the frequency with which those constraints are violated. Rather, they appear to be what they are: namely, limitations on the extent to which (or the ways in which) that agent-neutral goal of minimization can legitimately be pursued.

In the antepenultimate sentence of the passage quoted above, Scheffler refers to one of the earlier discussions in his article. That earlier discussion, which I have quoted in $\S 3.2$, correctly contends that deontologists are committed to the No Contraventions Principle. Because the No Contraventions Principle is centered on the distinction between none and some rather than on the distinction between fewer and more - in other words, because it is an absolutist principle rather than a minimizing principle - the commitment of deontologists to it scarcely renders puzzling their insistence that agent-centered prohibitions impose moral obligations even when the fulfillment of those obligations will increase the incidence of violations of the prohibitions. Of course, an insistence on that point is at odds with the Minimization Principle. Were deontologists committed to that latter principle, as Scheffler clearly appears to be assuming in the extract quoted in this subsection, they would indeed be muddled. However, as I have sought to underscore, deontologists squarely repudiate the Minimization Principle. Scheffler himself has grasped as much in the earlier portion of his article, by correctly attributing to deontologists an embrace of the No Contraventions Principle.

\subsection{The maximizing conception of rationality redux}

Scheffler fails in his efforts to show that deontologists have espoused some positions that are in tension with each other, and specifically he fails in his efforts to show that deontologists are committed to any consequentialist precepts such as the Minimization Principle. However, his central worry about the inconsistency between deontological doctrines and the maximizing conception of rationality might seem to have withstood my ripostes. While granting that deontologists are not mired in the confusion of which Scheffler accuses them, a defender of Scheffler might nonetheless contend that deontological doctrines are deeply problematic because they clash with a mode of practical rationality that pervades our everyday lives. Such a defender might feel that I have not yet parried Scheffler's critique on that vital point.

Two main replies to such a line of defense are appropriate; the present subsection will advance one of those replies, and my next subsection will advance the other. First, then, we need to pin down what the maximizing conception of rationality is. In particular, we need to pin down the import of the 'ceteris paribus' clause 
in Scheffler's exposition of that conception of practical rationality. On the one hand, if the 'ceteris paribus' clause indicates that any maximizing quest is morally impermissible when such a quest contravenes some deontological restriction(s), then the maximizing mode of rationality does indeed pervade our everyday lives. However, when the 'ceteris paribus' clause is so construed, and when the permissibility of maximization is thus hemmed in by deontological constraints, the maximizing conception of rationality is fully consistent with any deontological doctrine. Contrary to what Scheffler proclaims, there is no tension whatsoever between the morality of common sense and the practical rationality of common sense.

On the other hand, if the 'ceteris paribus' clause does not incorporate any deontological constraints into the maximizing conception of rationality, and if the proponents of that conception therefore hold that the permissibility of maximizing quests is not bounded by any deontological restrictions, then it is far from clear - to say the least - that the maximizing conception of rationality does encapsulate a mode of reasoning which is widely endorsed in our everyday practices. Scheffler does not offer one whit of evidence to support the view that an unrestricted approach to maximization is a mode of reasoning that permeates those practices. Moreover, at the outset of his article he concedes that 'the common-sense morality of our culture is substantially deontological in content'. He subsequently refers to deontological constraints as 'the morality of common sense', and he suggests that 'agent-centered restrictions are congenial to the common-sense morality of our culture' and that 'the restrictions thus embody constraints on practical reasoning that seem to us natural and intuitively appealing' (1988, pp. 243, 251, 259). Although he then goes on to assert that the unrestricted approach to maximization is likewise 'a very powerful form of thought which itself occupies a central place within what we recognize as human practical rationality' and that it is 'a process of reasoning that itself seems natural and intuitively compelling’ (1988, p. 259), he provides no substantiating evidence for these claims about unconstrained maximization.

Hardly in need of confirmatory evidence is the notion that a maximizing orientation within the limits of deontological restrictions is a form of practical rationality that suffuses our everyday practices. Far more dubious is the notion that those practices are similarly suffused by a maximizing orientation without any such limits. Unless people in Western societies are so obtuse as to participate frequently in practices where they forget how congenial agent-centered restrictions are to the common-sense morality of their culture, they are not likely to embrace an unrestricted approach to maximization in a wide range of everyday contexts. In other words, whereas Scheffler contends that the morality of common sense clashes with the rationality of common sense, the real clash lies between the morality of common sense and his misrepresentation of the rationality of common sense. If his exposition of the rationality of common sense is to be 
credible, its 'ceteris paribus' clause has to be construed as indicating that the permissibility of any maximizing quests is bounded by agent-centered restrictions.

\subsection{A return to moral optimality}

Though placatory torture and most other types of torture are always and everywhere morally wrong in all possible worlds, some possible instances of placatory torture are morally optimal. Those instances would occur under truly extreme circumstances where the consequentialist considerations in favor of the use of torture are redoubtably potent and urgent. Notwithstanding that the perpetration of placatory torture is morally wrong even in those circumstances, the gravity of the wrongness is so greatly extenuated as to render morally optimal the recourse to torturous techniques of placation. In a dire emergency such as that faced by Melvin, where the administration of torture to his wife Miranda is likely to be efficacious in sparing her from considerably worse mistreatment - and where no non-torturous methods of averting that worse mistreatment are available - the use of some torturous techniques can be less grave as a breach of a moral duty than the wholesale eschewal of those techniques.

In sum, despite my insistence on the absoluteness of the moral impermissibility of placatory torture, I have not lost sight of the force of consequentialist pressures. Although those pressures can never suspend the moral prohibition on such torture, they can substantially mitigate the gravity of transgressions of that prohibition. Their mitigating influence can sometimes (albeit very rarely) render such a transgression morally optimal as the least terrible course of conduct that is feasible in some dreadful predicament. Hence, although the maximizing conception of rationality has to encompass deontological restrictions to be credible as an encapsulation of a mode of reasoning that pervades everyday contexts, the maximizing impetus that is at the core of the conception does not disappear even when those restrictions are applicable. Its force is felt not at the basic level of the impermissibility of any conduct that contravenes those restrictions, but instead at the more fine-grained level of the gravity of such conduct.

While deontological constraints do significantly limit the range of circumstances in which any maximizing quests can legitimately be pursued, there is not a simple clash between those quests and those constraints. One reason for rejecting Scheffler's critique of deontology is that it posits a simple clash in which the demands of deontology have to give way if the demands of a maximizing orientation are to be duly acknowledged. By highlighting the extent to which consequentialist pressures can mitigate the gravity of transgressions of deontological prohibitions, and by indicating that those pressures can even render such transgressions morally optimal in certain extreme situations, this 
paper acknowledges the force of the consequentialist factors without retreating at all from its insistence on the absoluteness of the deontological prohibitions. Through attentiveness to the occurrence of moral conflicts and to the intricacies of the dynamics in those conflicts, ${ }^{15}$ we can discern that deontological doctrines are far more resourceful than Scheffler allows. Proponents of those doctrines can register the weightiness of consequentialist considerations - and can register the power of the maximizing conception of rationality that underpins those considerations - without flinching from the strictness of deontology. ${ }^{16}$

\section{References}

Darwall, S. (1986). ‘Agent-Centered Restrictions from the Inside Out,' Philosophical Studies 50: 291-319.

Feinberg, J. (1973). Social Philosophy (Englewood Cliffs, NJ: Prentice-Hall)

Finnis, J. (1980). Natural Law and Natural Rights (Oxford: Oxford University Press)

Gewirth, A. (1981). 'Are There Any Absolute Rights?’ Philosophical Quarterly 31: 1-16.

Kamm, F. (2007). Intricate Ethics (Oxford: Oxford University Press)

Kramer, M. (2004). Where Law and Morality Meet (Oxford: Oxford University Press)

Kramer, M. (2014). Torture and Moral Integrity (Oxford: Oxford University Press)

Kramer, M. (2016). 'Moral Conflicts, the "Ought Implies Can" Principle, and Moral

Demandingness', in M. van Ackeren and M. Kühler (eds.), The Limits of Moral Obligation

(London: Routledge), pp. 163-184

Kramer, M. (2017). Liberalism with Excellence (Oxford: Oxford University Press)

Nagel, T. (1979). Mortal Questions (Cambridge: Cambridge University Press)

Nagel, T. (1986). The View from Nowhere (Oxford: Oxford University Press)

Nozick, R. (1974). Anarchy, State, and Utopia (New York, NY: Basic Books)

Parfit, D. (1984). Reasons and Persons (Oxford: Oxford University Press)

Scheffler, S. (1985). 'Agent-Centered Restrictions, Rationality, and the Virtues,' Mind 94: 409-419.

Scheffler, S. (1988). 'Agent-Centered Restrictions, Rationality, and the Virtues', in S. Scheffler (ed.), Consequentialism and Its Critics (Oxford: Oxford University Press), pp. 243-260

Scheffler, S. (1994). The Rejection of Consequentialism revised edition (Oxford: Oxford University Press).

Williams, B. (1973). 'A Critique of Utilitarianism', in J.J.C. Smart and B. Williams. Utilitarianism: For and Against (Cambridge: Cambridge University Press), pp. 77-150.

15 For much more ample expositions of the nature of moral conflicts, see Kramer (2014, pp. 2-19; 2016).

16 I presented this paper at a workshop at the University of Münster in June 2018. I am extremely grateful to Marcel van Ackeren and Simon Derpmann for organizing the workshop, and to the participants whose incisive questions have led to a number of salutary modifications. I owe thanks as well to the two anonymous readers whose valuable comments have prompted some further modifications. 